\title{
Total body burden arising from a week's repeated dermal exposure to $\mathrm{N}, \mathrm{N}$-dimethylformamide
}

\author{
H-Y Chang, C-Y Tsai, Y-Q Lin, T-S Shih, W-C Lin
}

Occup Environ Med 2005;62:151-156. doi: 10.1136/oem.2004.016089

See end of article for authors' affiliations

....................

Correspondence to: Dr H-Y Chang, Department of Environmental and Occupational Health, Medical College, National Cheng Kung University, 138 Sheng-Li Road, Tainan 704, Taiwan h7154@mail.ncku.edu.tw

Accepted 21 October 2004
Background: Hazardous chemicals and their metabolites may accumulate in the body following repeated airborne exposures and skin contact.

Aims: To estimate the contribution of skin absorption to total body burden of $\mathrm{N}, \mathrm{N}$-dimethylformamide (DMF) across a working week in two groups with similar levels of respiratory exposure but dissimilar skin contact.

Methods: Twenty five workers in a synthetic leather (SL) factory, 20 in a copper laminate circuit board (CLCB) factory, and 20 age and sex matched non-DMF exposed subjects, were recruited. Environmental monitoring of DMF exposure via respiratory and dermal routes, as well as biological monitoring of preshift urinary $\mathrm{N}$-methylformamide (U-NMF), were performed for five consecutive working days.

Results: Environmental and biological monitoring showed no detectable exposure in controls. The average airborne DMF concentration (geometric mean (GM) 3.98 ppm, geometric standard deviation (GSD) 1.91 ppm), was insignificantly lower for SL workers than for CLCB workers (GM 4.49, GSD 1.84 ppm). Dermal DMF exposure and U-NMF values, however, were significantly higher for SL workers. A significant pattern of linear accumulation was found across a five day work cycle for SL workers but not for CLCB workers. Conclusions: Dermal exposure to DMF over five consecutive days of occupational exposure can result in the accumulation of a significant DMF body burden. The long term exposure response under both repeated and intermittent conditions of substantial skin exposure is worthy of note.
$\mathrm{R}$ epeated exposure to chemicals is common in many environmental and occupational settings. Such long term exposures have the potential to cause bioaccumulation and raise the risk of adverse health effects-both matters of public concern. ${ }^{1-3}$ Workers in the manufacturing industry typically have such a repeated pattern of exposure: normally they work eight hours per day, five days per week for about 40-50 weeks per year. Few studies have been conducted to explore the bioaccumulation of chemicals (body burden) arising from such repeated exposures. A better understanding of bioaccumulation is important, considering the large pool of workers repeatedly exposed in this way.

The problem of dermal exposure has increasingly received attention because workers may easily be exposed to chemical hazards repeatedly, via routine or unexpected skin contact. Moreover, the relative contribution of skin exposure to body burden has assumed greater importance over the past few decades as respiratory exposures have become better controlled and adequate ventilation provided for specific chemical hazards. Many chemicals commonly used in working environments (for example, pesticides, aromatic amines, and polycyclic aromatic hydrocarbons) have been investigated because of concerns about substantial on-the-job skin absorption. ${ }^{4}$

In this respect $\mathrm{N}, \mathrm{N}$-dimethylformamide (DMF) is worthy of further study, given its widespread use in industry, its toxicity, its ready absorption through the skin, and its potential for bioaccumulation. Overexposure to DMF can cause hepatotoxicity, ${ }^{5}$ alcohol intolerance, ${ }^{7-9}$ male reproductive cancers, and possibly embryotoxicity and teratogenicity in humans and animals. ${ }^{10-13}$ Our recent study ${ }^{14}$ further revealed that occupational exposure to DMF can disrupt sperm motility. Experiments in human volunteers have shown that DMF in vapour and in liquid form is readily absorbed through the skin. The average dermal absorption rate when a person's hand is exposed to liquid DMF has been estimated to be $9.4 \mathrm{mg} / \mathrm{cm}^{2} \mathrm{~h}$. Our recent study ${ }^{15}$ of 75 workers from four DMF related factories showed that dermal exposure makes a substantial contribution to the total body burden of DMF in an actual working environment. Finally, several lines of evidence suggest that DMF might have a longer elimination half life when absorbed through the skin than through the respiratory tract. ${ }^{16-18}$ A longer half life implies slower elimination and a greater potential for bioaccumulation of DMF metabolites through dermal exposure than from respiratory exposure.

Biological monitoring is a good means of estimating the total body burden following chemical exposure. ${ }^{19}$ For DMF, the American Conference of Governmental Industrial Hygienists $(\mathrm{ACGIH})^{20}$ in the USA and the Deutsche Forschungsgemeinschaft (DFG) in Germany ${ }^{21}$ recommend that urinary levels of $\mathrm{N}$-methylformamide (NMF), one of the biotransformation products of DMF in humans, be used as the biomarker of total body burden. The half life of U-NMF is relatively short (about five hours). ${ }^{22}$ As the concentration of biomarker fluctuates during working hours, its pre-shift value is a more reliable marker of bioaccumulation than its post-shift value. ${ }^{23}{ }^{24}$ One challenge, however, in evaluating the total body burden of DMF is how to separate the dermal and respiratory contributions in the actual occupational setting.

From the databank of the Taiwan National Surveillance Programme on DMF related Industries, we chose two DMF exposed groups with similar airborne levels but different patterns of dermal exposure. After a single monitoring in both factories, field validation data showed that the airborne DMF values at each site were comparable to one another. We then monitored airborne and dermal exposure to DMF and

Abbreviations: $C L C B$, copper laminate circuit board; DMF, N,Ndimethylformamide; GM, geometric mean; GSD, geometric standard deviation; NMF, N-methylformamide; SL, synthetic leather 
Main messages

- Respiratory exposure to DMF, at about half the permissible exposure limit for five consecutive days, does not raise a worker's total body burden unless skin exposure is also substantial.

- In workers whose hands are exposed to liquid DMF at an average daily concentration of $7.62 \mu \mathrm{g} / \mathrm{cm}^{2}$, the contribution of each additional exposure day to preshift U-NMF is $1.27 \mathrm{mg} / \mathrm{l}$, given a daily airborne exposure to DMF of about $4 \mathrm{ppm}$.

analysed pre-shift urinary NMF values for each individual over five consecutive days (Wl-W5) to determine the total body burden accumulation of DMF. Our objective was to determine the relative contribution of skin absorption to the accumulation of the DMF biomarker across a working week.

\section{MATERIALS AND METHODS}

\section{Subject selection and pioneer field investigation}

DMF is one of the major occupational hazards in Taiwan because of its toxicity and extensive use. In 1999, Taiwan's Labor Affairs Council began a multi-year nationwide surveillance programme to evaluate airborne levels in the workplace. After reviewing previous annual reports, we found that the airborne DMF levels in a synthetic leather (SL) factory and a copper laminate circuit board (CLCB) factory were close. Our walk-through investigation found that the manufacturing workers were exposed mainly to DMF. All the workers in the factories wore long-sleeved clothes in winter and short-sleeved clothes in other seasons. The workers in both factories wore no gloves most of the time during the work shift. The major discrepancy between the two factories was that the CLCB factory workers were rarely directly exposed to liquids containing DMF, but the SL factory workers were frequently so exposed.

We recruited 25 SL factory workers and 20 CLCB factory workers for the DMF exposed groups, and, from a nearby polybutadiene latex factory, 20 age and sex matched workers not exposed to DMF as controls for this study. A questionnaire asking about age, work history, medical history, smoking and alcohol drinking habits, and other potential sources of exposure to DMF was administered during personto-person interviews. The SL workers and controls worked Monday to Friday (W1-W5), and the CLCB workers, during our study period, worked seven days per week in the mass production season. None of the participants had self-reported or physician documented and diagnosed liver or kidney disorders. Throughout the study period, none of the study participants wore a respirator, nor worked or went back to their factories during off-work hours. No one was exposed to possible DMF containing household products such as printing ink, shoe polishing gel, or paint stripper, according to questionnaires and personal interviews. All participating workers were asked not to imbibe alcohol during the study week. Each participant read and signed the consent forms approved by our institution's Institutional Review Board before the study began.

\section{Environmental monitoring of airborne and dermal exposure to DMF}

Airborne monitoring of DMF exposure covering the full work shift was implemented on an individual basis for each exposed participant for five consecutive days (from Wl to W5). Environmental monitoring of the three factories was performed in the same month at one week intervals.

\section{Policy implications}

- Strict avoidance of direct contact with DMF containing liquids is important, as skin exposure is a substantial cause of raised total body burden.

- The long term health effects in those who undergo repeated dermal exposure to DMF should be evaluated.

Determination of airborne exposure to DMF was done as previously described. ${ }^{15}$ In brief, a passive badge containing activated charcoal (3M 3500; 3 M Co., St Paul, MN, USA) worn on the right collar of each participant throughout the working period was used as a sampling adsorbent. The charcoal was extracted with $1.5 \mathrm{ml}$ extraction solvent composed of carbon disulphide (HPLC grade; Tedia, Fairfield, $\mathrm{OH}$, USA) and n-pentanol (American Chemical Society certified; Fisher Scientific, Pittsburgh, PA, USA) with the ratio $80 \%: 20 \%(\mathrm{v} / \mathrm{v})$ for 30 minutes, and a gas chromatograph (GC) equipped with a thermionic-sensitive detector (Varian 3600 CX GC/TSD; GenTech Scientific, Inc., Arcade, NY, USA) coupled to an auto-sampler (Varian 8200 CX; GenTech) was used in instrumental analysis. The limit of detection was $0.53 \mu \mathrm{g} / \mathrm{ml}$. All sample analyses were completed within two weeks of sample collection.

Personal dermal exposure to DMF was also monitored for each exposed participant for five consecutive days. After the factory walk-through and consultation with the participating workers, the investigators decided that the possible skin exposure sites for workers were hands and forearms, because their other body areas were either covered by clothing or unlikely to be exposed to any material at work. Determination of dermal exposure to DMF was done as previously described. ${ }^{15}$ In brief, a $10 \mathrm{~cm}^{2}$ patch of adhesive tape $(3 \mathrm{M}$ Series $845,2.5 \mathrm{~cm} \times 4 \mathrm{~cm}$ ) was applied right before the end of the work shift to assess dermal exposure during the workday. For hands, the tape patch was applied on the palm and dorsal side of both hands. For forearms, it was applied on the ventral part of both arms. To avoid the possibility of contamination, we used forceps to apply all tape patches. We also applied identical tape patches on the paravertebral area of the 7th cervical spine process as the control because this area was fully covered by clothing and was on the opposite side of the body from the contaminant source. Immediately after the patch was removed, it was transferred to a $10 \mathrm{ml}$ vial containing $5 \mathrm{ml}$ of desorption solvent. The vial was immediately sealed with a Teflon cap and stored in a freezer until GC analysis. The limit of detection was $0.03 \mu \mathrm{g} / \mathrm{ml}$.

Airborne and dermal exposure monitoring of the controls was conducted only on the first and the last workdays (W1 and W5).

\section{Biological monitoring strategies and urine analysis}

Urine specimens were collected from each worker at pre-shift for five consecutive days in parallel with environmental sampling. For the control group, first voided urine samples on only WI and W5 were collected. Spot urine was collected in pre-cleaned polyethylene plastic cups. To prevent contamination of the urine samples, all participants were asked to wash their hands with a detergent we provided before urine collection. The voiding time and creatinine level for each urine sample were measured and recorded. Right after collection, aliquots of each urine sample were kept at $4^{\circ} \mathrm{C}$ and analysed within 24 hours for creatinine concentration using the Jaffe reaction in an autoanalyser. ${ }^{25}$ Samples with a creatinine concentration $>3.4 \mathrm{~g} / \mathrm{l}$ or $<0.3 \mathrm{~g} / \mathrm{l}$ were excluded 


\begin{tabular}{|c|c|c|c|c|c|}
\hline Subjects & $n$ & $\begin{array}{l}\text { Age }^{*} \\
\text { Mean (range) }\end{array}$ & $\begin{array}{l}\text { Working duration* } \\
\text { Mean (range) }\end{array}$ & $\begin{array}{l}\text { Cigarefte } \\
\text { smoking } \\
(\%)\end{array}$ & $\begin{array}{l}\text { Alcohol drinkingt } \\
\text { (\%) }\end{array}$ \\
\hline \multicolumn{6}{|l|}{ Exposed } \\
\hline $\mathrm{SL}$ & 25 & $\begin{array}{l}37.44 \\
(24-55)\end{array}$ & $\begin{array}{l}6.92 \\
(1-20)\end{array}$ & $66.7 \%$ & $41.7 \%$ \\
\hline CLCB & 20 & $\begin{array}{l}32.95 \\
(22-45)\end{array}$ & $\begin{array}{l}5.7 \\
(1-17)\end{array}$ & $50.0 \%$ & $45.0 \%$ \\
\hline Reference & 20 & $\begin{array}{l}34.20 \\
(28-41)\end{array}$ & $\begin{array}{l}6.40 \\
(1-22)\end{array}$ & $55.0 \%$ & $35.0 \%$ \\
\hline
\end{tabular}

*No significance was found among the three groups $(p>0.05)$ by one way ANOVA test. †No significance was found among the three groups $(p>0.05)$ by $\chi^{2}$ test.

from data analysis due to possible renal function disorders in test participants. ${ }^{26}$ Before GC analysis for urinary NMF, the urine samples were stored at $-80^{\circ} \mathrm{C}$. All samples were analysed within a month of collection. Urine preparation and analysis methods were as previously published. ${ }^{15} 27$ In brief, promptly thawed urine samples at $37^{\circ} \mathrm{C}$ were centrifuged at $5000 \mathrm{rpm}$ for 20 minutes. The supernatant $(0.5 \mathrm{ml})$ was added to $0.5 \mathrm{ml}$ methanol (HPLC grade; Tedia), kept in a $4^{\circ} \mathrm{C}$ ice bath for 15-20 minutes, and then further centrifuged at $5000 \mathrm{rpm}$ for 10 minutes before GC analysis. We found the limit of detection was $0.33 \mu \mathrm{g}$ per injection. All the airborne, dermal, and urine samples were coded with a series number; the technician in charge of chemical analysis of DMF/NMF was blind to the status of the sample origin.

\section{Data analysis}

The Shapiro-Wilks W test was performed to assess the normality of the concentration distributions of airborne, dermal, and biological monitoring samples. The concentration distributions of DMF in air (A-DMF), on hands ( $\mathrm{H}-$ $\mathrm{DMF}$ ), on forearms (F-DMF), and in urinary NMF (U-NMF) were all log normally distributed. Thus, the geometric mean (GM) and geometric standard deviation (GSD) were used to present the central tendency and degree of dispersion of the measurements. Natural log transformed data were used throughout the data analyses. One way analysis of variance (ANOVA) and the F-test were used for determining whether day-to-day variation was significant for A-DMF, H-DMF, FDMF, and U-NMF. The Spjotvoll/Stoline test (Tukey HSD for unequal $\mathrm{N}$ test) was applied in post hoc comparisons. A simple linear regression test was used to explore the linear accumulation trends of U-NMF over the five day period. Statistica Software (release 6; StatSoft, Inc., Tulsa, OK, USA) was used for all statistical analyses. Statistical significance was set at $\mathrm{p}<0.05$.

\section{RESULTS}

All the study participants were male. The workers in the SL factory were slightly older, had been working longer, and smoked more frequently than those in the CLCB factory and the controls, but the differences were not significant (table 1).

The airborne and dermal measurements monitoring DMF exposure and the U-NMF tests from the control participants showed no detectable values, suggesting that both internal and external exposure to DMF were nil and could be ignored. The controls were excluded from further data analysis.

For the DMF exposed groups, all measurements performed on the paravertebral area of the 7 th cervical spine process were below the limit of detection, indicating neither background level nor contamination in the assessment of dermal exposure during the field study. The average breathing zone air concentrations monitored from Monday to Friday for SL workers (GM 3.98, GSD 1.91) were insignificantly lower than those for CLCB workers (GM 4.49, GSD 1.84) (table 2). The day-to-day variability for these two separate groups across the weekdays was found to be insignificant, indicating that their daily respiratory exposure to DMF was relatively constant. Dermal exposure to DMF via the hands and forearms, however, was significantly greater in SL workers than in CLCB workers. The average DMF concentration across five consecutive working days was significantly higher on hands $\left(7.62 \mu \mathrm{g} / \mathrm{cm}^{2}\right)$ than on forearms $\left(0.41 \mu \mathrm{g} / \mathrm{cm}^{2}\right)$ for SL workers (table 3), and the significant day-to-day differences on the hands of SL workers were found between W1 $v$ W3-W5, W2 $v$ W3-W5, W3 $v$ W4-W5, and W4 $v$ W5. The significantly greater DMF concentrations on hands than on forearms $(p<0.001)$ remained consistent for each day, suggesting that hand exposure to DMF is the more frequent and important site for dermal exposure. Dermal exposure to DMF for CLCB workers was much lower. Only 5 of $92(6.5 \%)$ and 3 of $90(3.3 \%)$ measurements showed a detectable amount of DMF on the hands and forearms, respectively, of CLCB workers.

Table 2 Air concentrations (ppm) of N,N-dimethylformamide (DMF) across five consecutive days for the workers in a synthetic leather (SL) factory and a copper laminate circuit board (CLCB) factory*

\begin{tabular}{|c|c|c|c|c|c|c|c|c|}
\hline & Weekday & W1 & W2 & w3 & W4 & W5 & W1-W5 & F value ${ }^{*}$ \\
\hline \multirow[t]{3}{*}{ SL } & $n$ & 22 & 22 & 23 & 25 & 25 & 117 & \\
\hline & GM (GSD) & $3.98(1.77)$ & 3.54 (1.95) & $5.13(1.91)$ & $3.24(2.00)$ & 4.45 (1.82) & 3.98 (1.91) & \\
\hline & Range & $1.28-14.39$ & $0.62-12.03$ & $1.28-21.60$ & $0.27-10.79$ & $0.78-16.69$ & $0.27-21.60$ & 1.92 \\
\hline \multirow[t]{3}{*}{$\mathrm{CLCB}$} & $n$ & 18 & 20 & 17 & 19 & 19 & 93 & \\
\hline & GM (GSD) & $4.42(1.90)$ & 4.56 (1.52) & $4.82(2.03)$ & $4.01(1.66)$ & 4.44 (1.82) & $4.49(1.84)$ & \\
\hline & Range & $1.20-17.78$ & $1.86-11.43$ & $0.32-21.62$ & $0.87-11.97$ & $0.28-18.33$ & $0.28-21.62$ & 1.20 \\
\hline
\end{tabular}

${ }^{*}$ The airborne concentrations of DMF collected from the reference groups on W1 and W5 for each subject were under detection limit $(0.53 \mu \mathrm{g} / \mathrm{ml})$. $\mathrm{tp}>0.05$ by one way ANOVA test. 
Table 3 Dermal exposure levels of $N, N$-dimethylformamide (DMF) on hands and forearms $\left(\mu \mathrm{g} / \mathrm{cm}^{2}\right)$ in five consecutive days for the workers in a synthetic leather (SL) factory and a copper laminate circuit board (CLCB) factory*

\begin{tabular}{|c|c|c|c|c|c|c|c|c|}
\hline & Weekday & W1 & W2 & W3 & W4 & W5 & W1-W5 & F value \\
\hline \multicolumn{9}{|l|}{$\overline{S L}$} \\
\hline \multirow[t]{4}{*}{ Hand } & $\mathrm{n}$ & 23 & 24 & 22 & 23 & 24 & 116 & \\
\hline & $\mathrm{GM}$ (GSD) & $9.39(2.89)$ & $9.68(3.49)$ & $6.25(4.15)$ & $14.01(3.70)$ & $3.13(3.26)$ & $7.62(3.96)$ & \\
\hline & Range & $0.63-94.63$ & $0.12-51.56$ & $0.20-96.71$ & $0.67-79.04$ & $0.14-38.60$ & $0.12-96.71$ & $5.42^{\star \star \star}$ \\
\hline & ND (\%) & $0.0 \%$ & $0.0 \%$ & $0.0 \%$ & $0.0 \%$ & $0.0 \%$ & $0.0 \%$ & \\
\hline \multirow[t]{4}{*}{ Forearm } & $\mathrm{n}$ & 23 & 24 & 24 & 23 & 24 & 118 & \\
\hline & GM (GSD) & $0.21(5.21)$ & $0.87(1.76)$ & $0.62(1.22)$ & $0.93(4.69)$ & $0.17(4.23)$ & $0.41(4.22)$ & \\
\hline & Range & $0.09-4.95$ & $0.14-4.95$ & $0.16-1.41$ & $0.18-37.10$ & $0.14-12.60$ & $0.09-37.10$ & 2.32 \\
\hline \multirow{2}{*}{\multicolumn{2}{|c|}{ ND (\%) }} & $0.0 \%$ & $0.0 \%$ & $0.0 \%$ & $0.0 \%$ & $0.0 \%$ & $0.0 \%$ & \\
\hline & & $p<0.001$ & $p<0.001$ & $p<0.001$ & $p<0.001$ & $p<0.01$ & $p<0.001$ & \\
\hline \multicolumn{9}{|l|}{ CLCB } \\
\hline \multirow{4}{*}{ Hand } & $\mathrm{n}$ & 18 & 19 & 17 & 19 & 19 & 92 & \\
\hline & GM (GSD) & NA & NA & NA & NA & NA & NA & \\
\hline & Range & ND-0.09 & ND- 0.13 & ND & ND- 0.20 & ND- 0.16 & ND- 0.20 & - \\
\hline & ND (\%) & $94.4 \%$ & $89.5 \%$ & $100.0 \%$ & $89.5 \%$ & $94.5 \%$ & $93.5 \%$ & \\
\hline \multirow{4}{*}{ Forearm } & $n$ & 19 & 18 & 17 & 18 & 18 & 90 & \\
\hline & GM (GSD) & NA & NA & NA & NA & NA & NA & \\
\hline & Range & ND-0.06 & ND- 0.22 & ND & ND & ND & ND- 0.22 & - \\
\hline & ND (\%) & $94.5 \%$ & $88.9 \%$ & $100.0 \%$ & $100.0 \%$ & $100.0 \%$ & $96.7 \%$ & \\
\hline Test† & & NA & NA & NA & NA & NA & NA & \\
\hline
\end{tabular}

*The concentrations of DMF on hands and on forearms collected from the reference groups on W1 and W5 for each subject were below the detection limit. †Tests between hands and forearms by Student's $t$ test. ${ }^{* * *} p<0.01$ by one-way ANOVA test. In post hoc comparisons, the significant day-to-day differences for hands in SL were found between (W1 v W3, W4, W5), (W2 $v$ W3, W4, W5), (W3 $v$ W4, W5), and (W4 v W5).

$\mathrm{NA}$, not available; ND, not detectable, which means less than limit of detection $(\mathrm{LOD}=0.03 \mu \mathrm{g} / \mathrm{ml})$, when calculating the GM and GSD, ND was designated as a half of LOD. ND(\%), the proportion of the test samples below LOD.

The average U-NMF concentrations at pre-shift across five consecutive days were 0.98 (4.13) $\mathrm{mg} / \mathrm{l}$ for SL workers, significantly $(\mathrm{p}<0.001)$ higher than 0.32 (3.32) $\mathrm{mg} / \mathrm{l}$ for CLCB workers (table 4). Moreover, the day-to-day variation of U-NMF showed different patterns for the two occupational settings. U-NMF concentrations in SL workers revealed significant day-to-day variability across a week $(\mathrm{p}<0.001$; one way ANOVA), but no significant day-to-day variability was found for CLCB workers.

Two approaches to the examination of the DMF body burden accumulation for SL and CLCB workers were applied. First, the body burden increment of DMF between two days $\left(\mathrm{U}-\mathrm{NMF}_{\mathrm{di}}\right)$ was derived by the following equation to assess whether biomarker levels had increased relative to the increasing day interval (di):

- $\mathrm{U}-\mathrm{NMF}_{\mathrm{di}}=\left(\mathrm{U}-\mathrm{NMF}_{\mathrm{Wk}}-\mathrm{U}-\mathrm{NMF}_{\mathrm{W}(\mathrm{k}-\mathrm{i})}\right), \mathrm{k}=2-5$, di $=1-4$

where $\mathrm{U}-\mathrm{NMF}_{\mathrm{di}}$ is the increment in body burden after di $(=1-4)$.

The differences in U-NMF increased significantly in relation to the increases of the difference of the interval between two urination days (by simple linear regression, $\mathrm{p}<0.001)$ for SL workers. However, no significant differ- ences between any two urination days for CLCB workers were found by one way ANOVA (fig 1). Second, a simple linear regression test was performed using the natural log transformed U-NMF value as the dependent variable and the day of exposure as the independent variable. A statistically significant coefficient of correlation $(r=0.39$, $p<0.001)$ and a positive slope $(0.25)$ were found for the SL group (table 5), suggesting a linear accumulation through continuous day-by-day exposure across a five day work cycle. Thus, for SL workers exposed to both liquid and airborne DMF, the contribution of each additional exposure day to UNMF at pre-shift was $1.27 \mathrm{mg} / \mathrm{l}$ (after anti-log conversion) given a daily airborne exposure of about $4 \mathrm{ppm}$ DMF. No statistically significant correlation was found for CLCB workers with a low level of dermal exposure to DMF.

\section{DISCUSSION}

Findings in previous studies about whether DMF accumulates across workdays in those occupationally exposed are inconclusive. One study that monitored airborne DMF exposure and urinary DMF biomarkers in 10 SL factory workers for three consecutive days reported airborne DMF levels similar to those in the present study, and a pre-shift trend of increasing U-NMF levels at pre-shift across three

Table 4 The average urinary NMF concentrations $(\mathrm{mg} / \mathrm{l}$ ) collected at pre-shift on five consecutive days for the workers in a synthetic leather (SL) factory and from a copper laminate circuit board (CLCB) factory*

\begin{tabular}{|c|c|c|c|c|c|c|c|c|}
\hline & Weekday & W1 & W2 & W3 & W4 & W5 & W1-W5 & $F$ test \\
\hline $\mathrm{SL}$ & $\begin{array}{l}\mathrm{n} \\
\text { GM (GSD) } \\
\text { Range }\end{array}$ & $\begin{array}{l}22 \\
0.25(5.88) \\
0.04-4.82\end{array}$ & $\begin{array}{l}22 \\
0.47(6.14) \\
0.04-11.92\end{array}$ & $\begin{array}{l}23 \\
1.58(4.94) \\
0.04-14.67\end{array}$ & $\begin{array}{l}25 \\
1.29(2.40) \\
0.26-9.90\end{array}$ & $\begin{array}{l}25 \\
2.82(2.09) \\
0.27-14.57\end{array}$ & $\begin{array}{l}117 \\
0.98(4.13) \\
0.04-14.67\end{array}$ & $5.86^{* * *}$ \\
\hline CLCB & $\begin{array}{l}\text { Weekday } \\
\mathrm{n} \\
\text { GM (GSD) } \\
\text { Range }\end{array}$ & $\begin{array}{l}\text { W1 } \\
19 \\
0.23(3.85) \\
N D *-3.33\end{array}$ & $\begin{array}{l}\text { W2 } \\
18 \\
0.35(3.12) \\
\text { ND-5.69 }\end{array}$ & $\begin{array}{l}\text { W3 } \\
17 \\
0.33(2.14) \\
\text { ND-2.08 }\end{array}$ & $\begin{array}{l}\text { W4 } \\
18 \\
0.37(1.17) \\
0.12-3.30\end{array}$ & $\begin{array}{l}\text { W5 } \\
18 \\
0.27(1.62) \\
\text { ND-3.12 }\end{array}$ & $\begin{array}{l}\text { W1-W5 } \\
90 \\
0.32(3.32) \\
\text { ND-5.69 }\end{array}$ & 2.31 \\
\hline
\end{tabular}

*The NMF concentrations collected at the first voided urine from the reference groups on W1 and W5 were under the detection limit. ${ }^{* * *} \mathrm{p}<0.001$ by one way ANOVA test.

$N D$, under the limit of detection (LOD=0.02 $\mathrm{mg} / \mathrm{l})$. 


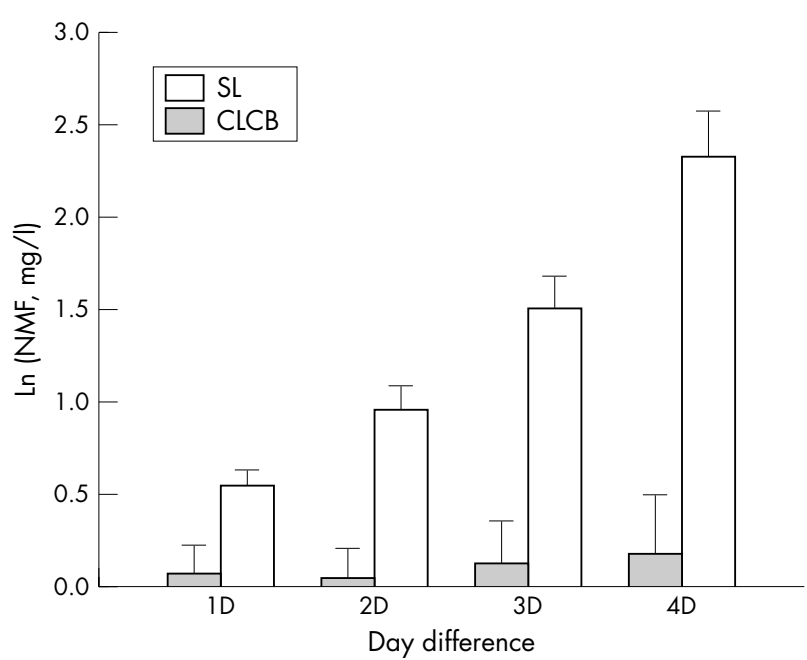

Figure 1 The differences in U-NMF levels $(\mathrm{mg} / \mathrm{l}$, natural log transformed) collected at pre-shift between 1,2, 3, and 4 day intervals (di). For di=1: U-NMF $F_{d 1}=\left(U-N M F_{W k}-U-N M F_{W(k-1)}\right), k=2-5$; for $\mathrm{di}=2: \mathrm{U}-\mathrm{NMF}_{\mathrm{d} 2}=\left(\mathrm{U}-\mathrm{NMF}_{\mathrm{Wk}}-\mathrm{U}-\mathrm{NMF}_{\mathrm{W}(\mathrm{k}-2)}\right), \mathrm{k}=3-5$; for $\mathrm{di}=3$ : U$\mathrm{NMF}_{\mathrm{d} 3}=\left(\mathrm{U}-\mathrm{NMF} \mathrm{F}_{\mathrm{Wk}}-\mathrm{U}-\mathrm{NMF}_{\mathrm{W}(\mathrm{k}-3)}\right), \mathrm{k}=4-5 ;$ for di $=4: \mathrm{U}-\mathrm{NMF}_{\mathrm{d} 4}=(\mathrm{U}-$ $\left.\mathrm{NMF}_{\mathrm{Wk}}-\mathrm{U}-\mathrm{NMF} \mathrm{F}_{\mathrm{W}(\mathrm{k}-4)}\right), \mathrm{k}=5$. The differences in U-NMF significantly increase in relation to the increases of the difference of the interval between two urination days (by simple linear regression, $p<0.001$ ) for SL workers. However, no significant differences between any two urination days for $\mathrm{CLCB}$ workers were found by one way ANOVA. U$\mathrm{NMF}$, urinary $\mathrm{N}$-methylformamide; $\mathrm{SL}$, synthetic leather; $\mathrm{CLCB}$, copper laminate circuit board.

days. $^{23}$ Another study of DMF biomarker accumulation measured airborne concentrations and urinary biomarkers of DMF exposure for four consecutive working days (Tuesday to Friday) in 23 polyacrylic fibre manufacturing workers. They found a $1.75 \mathrm{ppm}$ median concentration of airborne DMF and concluded that no accumulation occurred based on findings that daily pre-shift urine biomarker levels were always at baseline. ${ }^{22}$ Because those workers either had no contact with liquid DMF or were wearing protective equipment, their findings were consistent with ours for the CLCB workers: persons without substantial contact with liquid DMF will not have biomarker accumulation. The aforementioned studies, however, either did not monitor dermal exposure or had no compatible comparison groups with similar airborne but different dermal exposure levels. The findings from the current study, however, show that the accumulation of body burden of DMF exposure is likely to occur in a regular exposure scenario during a five consecutive workday cycle because of the following facts: (1) the significant increase of U-NMF following the interval of two urination days (fig 1); and (2) the significant linear trend of daily U-NMF for SL workers (table 5).

Table 5 Simple linear regression tests of urinary NMF $(\mathrm{mg} / \mathrm{l})$ levels with the number of monitoring day across the weekdays (W1-W5)

\section{Parameters of regression}

\begin{tabular}{llclll}
\cline { 2 - 5 } Factory & $\mathbf{n}$ & Intercept & Slope & $\boldsymbol{r}$ & $\mathbf{p}$ \\
\hline SL & 117 & -0.79 & $0.25^{\star * *}$ & $0.39^{* * *}$ & $<0.001$ \\
CLCB & $85^{*}$ & 2.23 & 0.78 & 0.04 & 0.72 \\
\hline
\end{tabular}

The data regarding the urinary U-NMF and A-DMF were naturally log transformed.

*Excluding the data for those skin exposures (hand or forearm) were detectable.
In the present study, we found no accumulation across five consecutive workdays in the pre-shift urine for CLCB workers in contrast to a clear linear accumulation for SL workers given the same working hours and personal protective equipment status, similar airborne DMF concentrations, and the same ethnicity. Therefore, the DMF body burden accumulation in SL workers can be attributed to their substantial dermal exposure to DMF during the manufacturing process.

The percutaneous absorption of DMF vapour in humans is possible. ${ }^{28} 29$ DMF is not a highly volatile compound (boiling point $150^{\circ} \mathrm{C}$ ), and we can hypothesise the predominance of the contribution of DMF liquid over DMF vapour in accumulation from dermal exposure. The finding that the total body burden of the exposure of a single hand to liquid DMF for 10 minutes is equivalent to exposure to $10 \mathrm{ppm}$ DMF vapour via both respiratory and dermal routes for eight hours $^{23}$ supports this hypothesis to some degree.

The half life of chemical elimination from the body absorbed by skin exposure is longer than that absorbed by the respiratory route. 2-Butylethanol in venous blood disappears almost immediately at the termination of the exposure through inhalation, although the venous blood concentrations resulting from skin exposure to 2-butylethanol remained for at least two hours subsequent to the cessation of dermal exposure. ${ }^{29}$ In many cases, intercellular lipids of the stratum corneum function reservoirs that preserve topical xenobiotics before they enter the circulatory system. ${ }^{30}$ This provides a scientific basis for longer half lives in the excretion of chemicals absorbed through the skin.

Nearly 200 chemical hazards in the ACGIH threshold limit value booklet ${ }^{20}$ have been marked with skin notations implying the possibility of skin absorption. For half a century, however, skin absorption has been largely ignored in exposure assessment, regulation setting, and, especially, hazard control. As occupational health standards become increasingly stringent, the contribution of skin absorption will be expected to become increasingly important. Dermal absorption of DMF may be more significant than respiratory tract absorption. Protection from skin exposure to such a strong skin permeable chemical is especially important. Wearing appropriate gloves is more effective than protective lotion against dermal exposure to liquid DMF in the occupational environment. ${ }^{31}$ Our recent study ${ }^{32}$ also showed that workers wearing impermeable rubber gloves exhibited a two thirds reduction in the total body uptake from exposure to 2-methoxyethanol, another skin penetrator like DMF. We therefore suggest that wearing appropriate impermeable gloves during high risk operations like mixing, loading, mounting, and machine cleaning, should be enforced with the highest priority.

DMF is oxidised into N-hydroxymethyl-N-methylformamide (HMMF) by cytochrome P4502El in humans, ${ }^{33}$ and then it is metabolised into a great number of metabolites, including $\mathrm{N}$-methylformamide (NMF). ${ }^{54-36} \mathrm{HMMF}$, the predominant metabolite (accounting for $50-80 \%$ of the absorbed dose), was difficult to identify owing to its easy thermodegradation into NMF during GC analysis. Thus, the U-NMF levels represent the sum of U-HMMF and UNMF. ${ }^{37}{ }^{38}$ More and more reports have concluded that methyl isocyante (MIC), the reactive intermediate of DMF metabolite from NMF, is the responsible compound exerting toxicity. ${ }^{59}$ The increasing trend of daily U-NMF over five consecutive days suggested that the accumulation of body burden tends to aggravate the DMF damage in humans. The long term exposure response under such repeated and intermittent conditions warrants more comprehensive prevention measures to reduce dermal exposure for those workers occupationally exposed to DMF. 


\section{Conclusions}

This study revealed significant accumulation of body burden from detectable dermal and respiratory occupational exposure to DMF for five consecutive workdays. It also showed that no respiratory accumulation occurred if workers were exposed only to airborne DMF. The long term exposure response under such repeated and intermittent conditions with substantial skin exposure warrants more comprehensive prevention measures to reduce dermal exposure for those workers occupationally exposed to DMF. This study also provided an evidence based finding that the importance of dermal exposure monitoring should not be overlooked in the exposure assessment strategies for chemical hazards.

\section{ACKNOWLEDGEMENTS}

This study was jointly funded by the Institute of Occupational Safety and Health, Council of Labor Affairs, Taiwan (project no. IOSH91A315) and the Taiwan National Science Council (grant no. NSC932320-B006). We thank all of the participants and their employers for their cooperation.

\section{Authors' affiliations}

H-Y Chang, C-Y Tsai, Y-Q Lin, Department of Environmental and Occupational Health, Medical College, National Cheng Kung University, Tainan, Taiwan

T-S Shih, Institute of Occupational Safety and Health, Council of Labor Affairs, Taipei, Taiwan

W-C Lin, Department of Applied Cosmetics Sciences, Chia-Nan University of Pharmacy and Science, Tainan, Taiwan

Competing interests: none declared

The study protocol was approved by the Institutional Review Board of the Medical College, National Cheng Kung University, before the research started. Each participant read and signed the consent forms before the study began.

\section{REFERENCES}

1 Glennemeler KA, Denver RJ. Sublethal effects of chronic exposure to an organochlorine compound on northern leopard frog (Rana pipiens) tadpoles. Environ Toxicol 2001;16:287-97.

2 Goh VH, Chia SE, Ong CN. Effects of chronic exposure to low doses of trichloroethylene on steroid hormone and insulin levels in normal men. Environ Health Perspect 1998;1061:41-4.

3 Pope CA 3rd. pidemiology of fine particulate air pollution and human health: biologic mechanisms and who's at risk? Environ Health Perspect 2000; 108(suppl 4):713-23.

4 Sartorelli P. Dermal exposure assessment in occupational medicine. Occup Med 2002;52:151-6.

5 Gescher A. Metabolism of N,N-dimethylformamide: key to the understanding of its toxicity. Chem Res Toxicol 1993;6:245-51.

6 Wrbitzky R. Liver function in workers exposed to N,N-dimethylformamide during the production of synthetic textiles. Int Arch Occup Environ Health 1999;72:19-25.

7 Chivers CP. Disulfiram effect from inhalation of dimethylformamide. Lancet 1978; 1:331.

8 Cox NH, Mustchin CP. Prolonged spontaneous and alcohol-induced flushing due to the solvent dimethylformamide. Cont Dermatol 1991;24:69-70.

9 Lyle WH, Spence TW, McKinneley WM, et al. Dimethylformamide and alcohol intolerance. $\mathrm{Br} J$ Ind Med 1979;36:63-6.

10 Anon. Reproductive toxicology. N, N-dimethylformamide. Environ Health Perspect 1997; 105(suppl 1):305-7.

11 Calvert GM, Fajen JM, Hills BW, et al. Testicular cancer, dimethylformamide and leather tanneries. Lancet 1990;336:1253-4

12 Fail PA, George JD, Grizzle TB, et al. Formamide and dimethylformamide: reproductive assessment by continuous breeding in mice. Reprod Toxicol 1998; 12:317-32.

13 Hansen $E$, Meyer $O$. Embryotoxicity and teratogenicity study in rats dosed epicutaneously with dimethylformamide (DMF). J Appl Toxicol 1990;10:333-8.

14 Chang HY, Shih TS, Guo YL, et al. Sperm function in workers exposed to N,Ndimethylformamide in synthetic leather industry. Fertil Steril 2004;81:1589-94.
15 Chang HY, Tsai CY, Lin YQ, et al. Urinary biomarkers of occupational N,Ndimethylformamide (DMF) exposure attributed to dermal exposure. J Exp Anal Environ Epidemiol 2004;14:214-21.

16 Johanson G, Boman A. Percutaneous absorption of 2-butoxy ethanol vapor in human subjects. Br J Ind Med 1991;48:788-92.

17 Poet TS, Weitz KK, Gies RA, et al. PBPK modeling of the percutaneous absorption of perchloroethylene from a soil matrix in rats and humans. Toxicol Sci 2002;671:17-31.

18 Thrall KD, Weitz KK, Woodstock AD. Use of real-time breath analysis and physiologically based pharmacokinetic modeling to evaluate dermal absorption of aqueous toluene in human volunteers. Toxicol Sci 2002;682:280-7.

19 Anon. Biological markers in environmental health research. Committee on Biological Markers of the National Research Council. Environ Health Perspect 1987;74:3-9.

20 American Conference of Governmental Industrial Hygienists (ACGIH). Dimethylformamide biological exposure indices (BEI) document, 6th edn. Cincinnati, $\mathrm{OH}$ : American Conference of Governmental Industrial Hygienists (ACGIH), 2000.

21 Deutsche Forschungsgemeinschaft. Maximale Arbeitsplatzkonezentrationen und biologische Arbeitsstofftoleranzwerte. Mitteilung 33, Senatskommission zur Prufunggesundheitsschadlicher Arbeitsstoffe. Weinheim, Germany: Wiley-VCH, 2000

22 Kafferlein HU, Goen T, Muller J, et al. Biological monitoring of workers exposed to N,N-dimethylformamide in the synthetic fibre industry. Int Arch Occup Environ Health 2000;73:113-20.

23 Lareo AC, Perbellini L. Biological monitoring of workers exposed to N-Ndimethylformamide. II. Dimethylformamide and its metabolites in urine of exposed workers. Int Arch Occup Environ Health 1995;67:47-52

24 Shih TS, Chou TC, Chang HY, et al. Accumulation of urinary 2thiothiazolidine-4-carboxylic acid (TTCA) among the workers occupationally exposed to a week-long exposure to carbon disulfide. Sci Tot Environ 2003;308:37-47.

25 Henry RJ, Cannon DC, Winkleman JW. Automated determination of serum and urine creatinine. In: Henry RJ, Cannon DC, Winkleman RJ, eds. Clinical chemistry, principles and techniques. New York, NY: Harper and Row, 1974:552-5.

26 Rosenberg J, Fiserova-Bergerova V, et al. Measurements in urine. In: Biological Exposure Indices Committee, eds. Topics in biological monitoring. Cincinnati, $\mathrm{OH}$ : American Conference of Governmental Industrial Hygienists (ACGIH), 1995:25-32.

27 Chang HY, Shih TS, Cheng CC, et al. The effects of co-exposure to methyl ethyl ketone (MEK) on the biological monitoring of occupational exposure to N,Ndimethylformamide (DMF). Int Arch Environ Occup Health 2003;76:121-8.

28 Mraz J, Nohova H. Percutaneous absorption of N,N-dimethylformamide in humans. Int Arch Occup Environ Health 1992:64:79-83.

29 Nomiyama T, Nakashima H, Chen LL, et al. N,N-dimethylformamide: significance of dermal absorption and adjustment method for urinary $\mathrm{N}$ methylformamide concentration as a biological exposure item. Int Arch Occup Environ Health $2001 ; 74: 224-8$.

30 Rougier A. In vivo percutaneous absorption: a key role for stratum corneum/ vehicle partitioning. In: Bronaugh RL, Maibach HI, eds. Percutaneous absorption drugs-cosmetics-mechanisms-methodology, 3rd edn. New York, NY: Marcel Dekker, 1995:193-214.

31 Lauwerys RR, Kivits A, Lhoir $M$, et al. Biological surveillance of workers exposed to dimethylformamide and the influence of skin protection on its percutaneous absorption. Int Arch Occup Environ Health 1980;45:189-203.

32 Chang HY, Shih TS, Chou JS, et al. Evaluation of the protective effectiveness of gloves from occupational exposure to 2-methoxy ethanol using the biomarkers of 2-methoxy acetic acid levels in the urine and plasma. Occup Environ Med 2004;61:697-702

33 Mraz J, Jheeta P. Investigation of the mechanistic basis of N, Ndimethylformamide toxicity: metabolism of $\mathrm{N}, \mathrm{N}$-dimethylformamide and its deuterated isotopomers by cytochrome P450 2E1. Chem Res Toxicol 1993;62:197-207.

34 Kafferlein HU, Angerer J. Simultaneous determination of two human urinary metabolites of N,N-dimethylformamide using gas chromatographythermionic sensitive detection with mass spectrometric confirmation. J Chromatogr B 1999;734:285-98.

35 Kestell $\mathbf{P}$, Gill MH, Threadgill MD, et al. Identification by proton NMR of $\mathrm{N}$ (hydroxymethyl)-N-methylformamide as the major urinary metabolite of $\mathrm{N}, \mathrm{N}$ dimethylformamide in mice. Life Sci 1986;38:719-24.

36 Mraz J, Nohova H. Absorption, metabolism and elimination of $\mathrm{N}, \mathrm{N}$ dimethylformamide in humans. Int Arch Occup Environ Health 1992;64:85-92.

37 Brindley C, Gescher A, Ross D. Studies of the metabolism of dimethylformamide in mice. Chem Biol Interact 1993;45:387-92

38 Scailteur V, DeHoffmann E, Buchet JP, et al. Study on in vivo and in vitro metabolism of dimethylformamide in male and female rats. Toxicology 1984;29:221-34.

39 Angerer J, Goen T, Kramer A, et al. N-methylcarbamoyl adducts at the Nterminal valine of globin in workers exposed to N,N-dimethylformamide. Arch Toxicol 1998;72:309-13. 